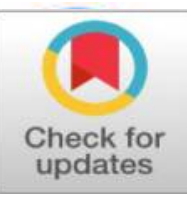

CRITICAL REVIEW

\title{
Mask in performing arts: The change in spiritual and artistic value through evolution of social context
}

\author{
Chollada Thongtawee*
}

Department of Theatre and Music, Faculty of Arts, Silpakorn University, Bangkok, Thailand

\author{
Keywords: \\ Mask \\ Performing arts \\ Spiritual development \\ Social context \\ Contemporary society \\ Capitalism
}

Received: 30 January 2016

Accepted: 2 February 2016

Published: 26 April 2016

\begin{abstract}
This research is a documentary research which aims to explore and collect data on the evolution of masks used in performing arts from the past to contemporary society. This would enhance understanding and awareness of value of masks in performing arts as well as the impacts of changing social contexts upon the usage of masks in performing arts and its adaptation towards such changes. The research result has shown that masks usage in performing arts has been evolving according to the dynamic changes of social contexts. Generally, masks are powerful tool which enable wearers/actors to be beyond/more than themselves. Masks are thus valuable in spiritual rituals and artistic performance. However, under the influence of Capitalism, these values of masks have been diminished to only colorful touristic attraction. This should be concerned by all parties involved for the spiritual evolution and benefits of this kind of art.
\end{abstract}

(c) 2016 The Author(s). Published by TAF Publishing.

\section{INTRODUCTION}

Masks have long been used in all cultures around the world since prehistoric times. They have been used for various purposes, especially spiritual, religious, and social ones. Some masks are considered as living beings, containing power within. Some masks serve as symbol for rite of passage: transition from childhood to adulthood. Masks have also been used in death-related rituals. They have been used to protect communities from evil spirit. They have also been used in war (Edson, 2005).

Besides spiritual and social purposes, masks have also been used for artistic purpose, especially in dramatic performance. They, with their spiritual-based quality, could serve as powerful tool for spiritual development through masked performing arts (Cameron and Patti, 2003).

\footnotetext{
*Corresponding author: Chollada Thongtawee

E-mail: littlegoldenwave@gmail.com
} 
However, within capitalist context, role of masks in contemporary performing arts/performance has been challenged and changed in response to the capitalistic demand, especially for touristic purpose.

\section{Scope and Conceptual Basis}

This study, using documentary research method, aims to explore data on masks in performing arts from the past to contemporary society, for deeper understanding and awareness of the value of mask usage and its adaptation and response to the challenging dynamic changes of social context.

The study is based on the conceptual basis that the development of human mind through performing arts has been dynamically changed in forms, processes and contents, in response to the changing paradigm of men through times. The emerging forms would always transcend and include the former ones (Guba, 1990). They could not be separated from their social contexts, being part of the whole (Goswami, 1993).

At the inner level, the learning process of an individual towards spiritual development through performing arts is composed of 3 levels, that is, the preparation/confrontation level when seeing the performance, the incubation of contents received, internalizing them within, and the illumination level, the manifestation of insight or wisdom gained from such incubation (Polanyi, 1969, 15-23; Nonaka and Hirotaka, 1995).

\section{STUDY RESULTS}

The study has shown that there has been usage of masked performing arts in various cultures around the world, which could be divided into 3 types according to the objectives of the usage, as following.

1. Spiritual purpose: masked performance for religious rites

2. Artistic purpose: masked performing arts/dramatic performance

3. Capitalist purpose: masked performance for commercial/touristic purpose

1.Spiritual purpose: masked performance for religious rites.

An over 6,000-year-old ancient Hindu painting has shown god wearing mask with horn. In Greek culture, in god Dionysus worshipping, masks were used (Corey, 1988, 11-16).

The Iroquois tribe of North America used mask performance for illness healing. In Himalayan culture, masks are used as medium to communicate with supernatural power (Thompson and Mary, 2003, 2).

In African cultures, animal masks have been used (Sannes, 1970, 2-6). Some African tribes believe that these animal masks could help them to communicate with the spirits of the forest and savannah (Hahner-Herzog et al, 2010, 45-48).

In the Latin American culture in the Andes, masks have been used for facial decoration of the deceased persons. Mask usage has been integrated to Christian belief, becoming part of the carnivals for Christian festivals (Thompson and Mary, 2003).

Generally, masks have been served as tools/medium for wearers to experience what it could be like to become 'someone else' (Edson, 2005, 3-4).

Artistic Purpose: Masked Performing Arts/Dramatic Performance

Masks have been used in dramatic performance and performing arts in various cultures throughout the world. Classical Greek actors wore masks with open 
mouths made of brass to increase and expand volume of voice for audience in outdoor theatres (Rozik, 2003, 1-3). During medieval period, masks were worn in Christian plays. The Commedia dell'arte masks have been the origins of clown mask-like facial painting up to present (Reinert, 1970, 3-8).

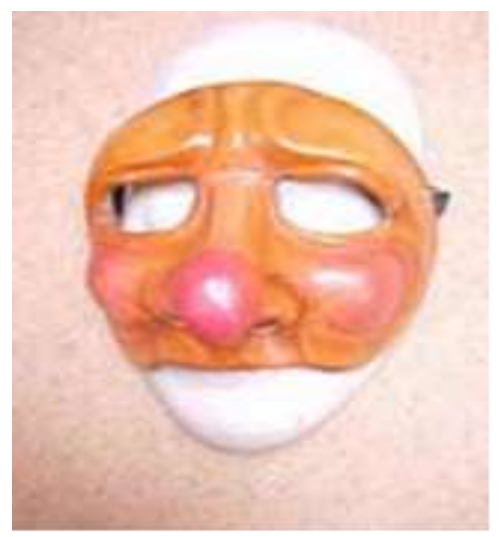

FIGURE. Commedia dell'arte mask (above)
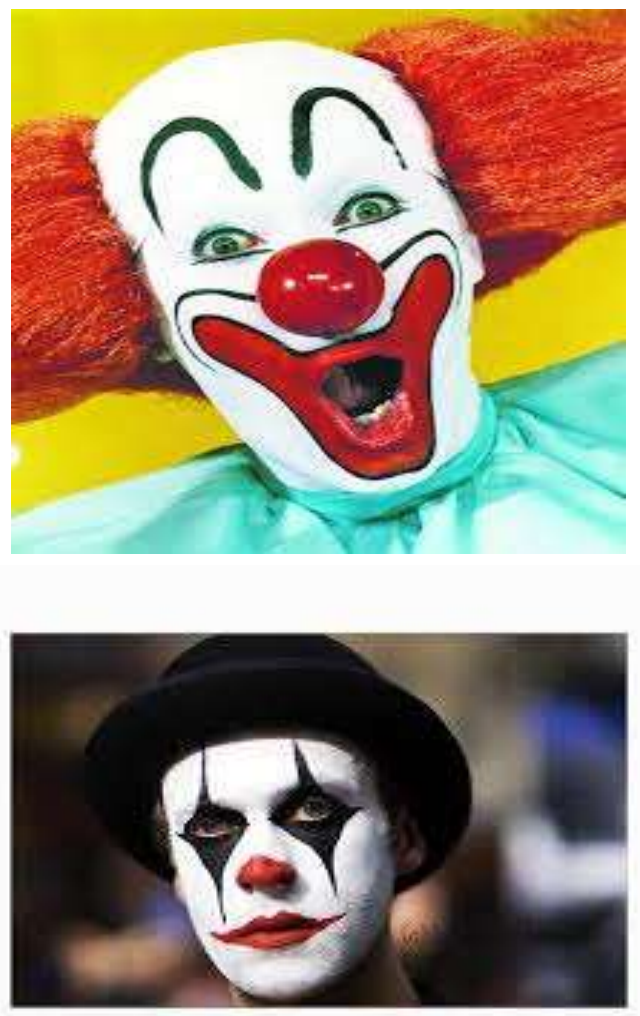

FIGURE 2. Clown's mask-like facial painting (above)

In India, masks have been worn in performing arts and reciting religious epics: the Ramayana and Mahabharata (Guénon, 2004, 14-15). In Indonesia, Topeng dance, influenced by Hindu Ramayana epic, masks have also been used (Belo, 1966, 5-7). 


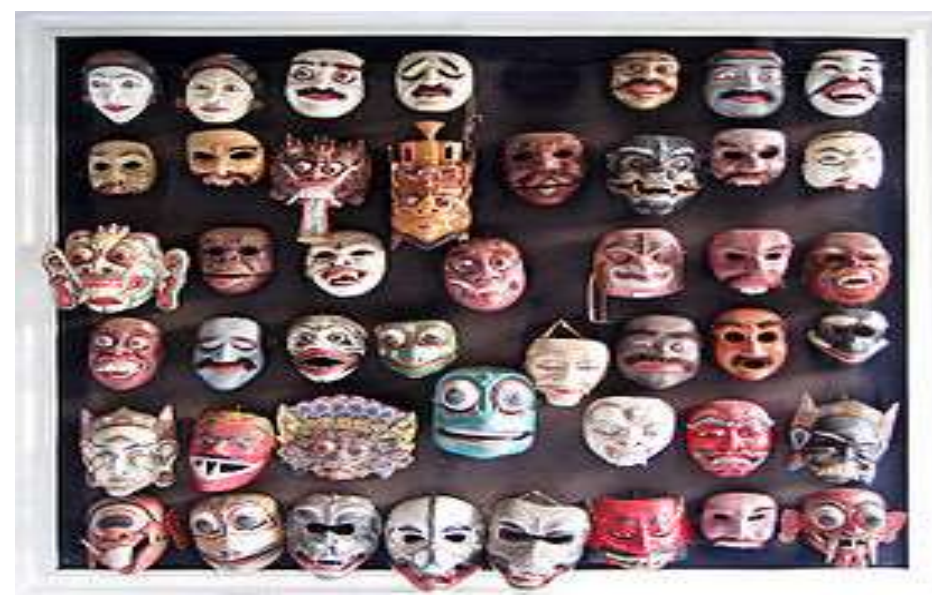

FIGURE 3. Masks of Topeng dance in Bali, Indonesia (above)

Masks have also been used in performing arts in China and Japan since ancient times. In Japan, Noh performance, developed from Gigaku and Bunraku performance, have generally been performed by male actors wearing masks. Noh masks represent gods, men, women, mad persons, and devils (Nakamura, 1971, 158-161). Japanese Kabuki performance has its roots in ancient performing arts. Nowadays, ancient masks of Kabuki have been replaced by mask-like facial painting (Kusano, 1967, 116-128).

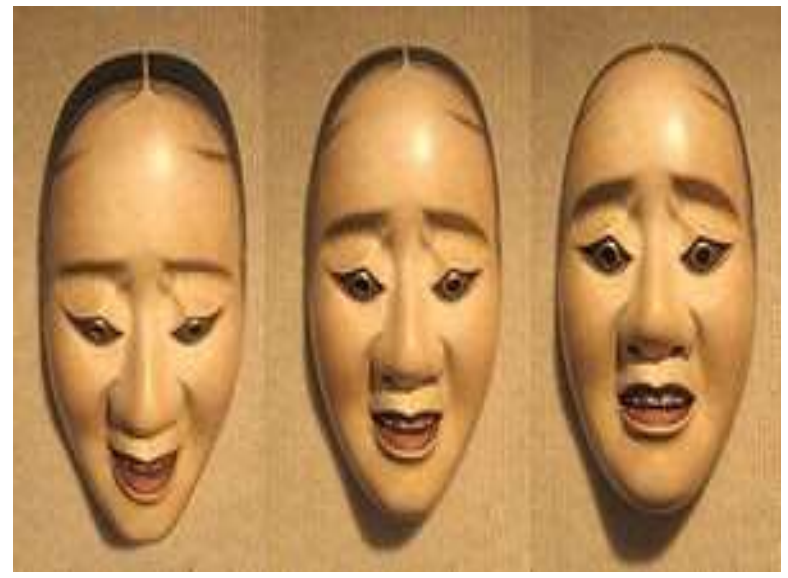

FIGURE 4. Noh's masks (above)

In Western contemporary performing arts, masks have also been used. From early 19th century, European artists used masks and puppets in their work: Alfred Jarry, Pablo Picasso, Oscar Schlemmer, as well as surrealistic and Dadaistic artists. In the 20th century, some dramatic artists used masks in their works: Edward Gordon Craig and Jacques Copeau.

Craig had influenced other dramatic artists like Bertolt Brecht, Jean Cocteau, as well as later artists like, Peter Brooks and Jerzy Grotowski to revive and restore ritualistic aspects of the theatre. Jacques Copeau used mask to free actors from the "excessive awkwardness" in acting. His method had influenced his 
students, like Etienne Decroux, Jean Daste, and Jacques Lecoq (Callery, 2001, 1415; Schechner, 1988).

Lecoq developed 'neutral mask' to be used in actors' rehearsal. This mask was designed to help students/actors to be more open in their acting. This neutral mask has had great influence on contemporary dramatists around the world (Lecoq, 2002).

Capitalist Purpose: Masked Performance for Commercial/Touristic Purpose In comparison to previously more spiritual-based paradigms, Capitalism could be considered as emerging from mechanistic scientific paradigm which believes in concrete reality of material world. With advanced technologies and scientific inventions, human beings, for the first time in history, could enjoy material pleasure almost without limit. This has somehow created ecological and social crisis, which in turn, has affected human holistic health in contemporary age (Smith and Mike, 2006, 22-36).

Under this capitalist influence, the spiritually powerful and sacred dramatic performance, like masked performing arts, could greatly attract tourists, and thus serve commercial purpose. This could be seen in several cultures. One of the case stories is the performance of 'Pi Ta Khon' in Dansai district, Loei province of Thailand.

The Case Study of a Thai Masked Performing Arts of 'Pi Ta Khon' Within Capitalist Context

The 'Pi Ta Khon' masked performing arts is a major performance which is part of the 'Boon Pra Vhet' annual Buddhist festival of Dansai district, Loei province, in the northeastern part of Thailand. This festival celebrates the return of Prince Vessandorn, the last incarnation of Lord Buddha, to his kingdom after several years of exile. These masked actors performing as ghosts following the Prince back to his city, eventually discard all the evils at the end of the ceremony and convert to the virtuous path of Buddhism.

In former times, the masked actors would throw their ghost masks and costumes down the river at the end of the religious parade as the symbol of discarding the evil path (Vallibhotama, 2007, 231).

However, under capitalist influence and the demand of tourist, through the promotion of governmental touristic office, these ghost masks have been sold at the end of the ceremony to tourists at high price for private collection due to their colorful, exotic design. There have also been the commercial making of these ghost masks to be sold as souvenirs in all sizes and forms including puppets and coffee mugs.

In the former times, ghosts' costumes and masks would be made from old, used household tools and cloth, painted with dulled natural color like charcoal. Nowadays, with touristic influence, their costumes and masks have been made from new, colorful cloth and tools, painted with bright chemical paints for lasting collection.

The debate has been going on whether these changes could be considered as 'development' for Pi Ta Khon performing arts as well as spiritual and social development of the community. This governmental touristic promotion has obviously brought in high income to local people. However, the importance of 
Buddhist preaching through this ritual of Pi Ta Khon performance has also been greatly lessened.

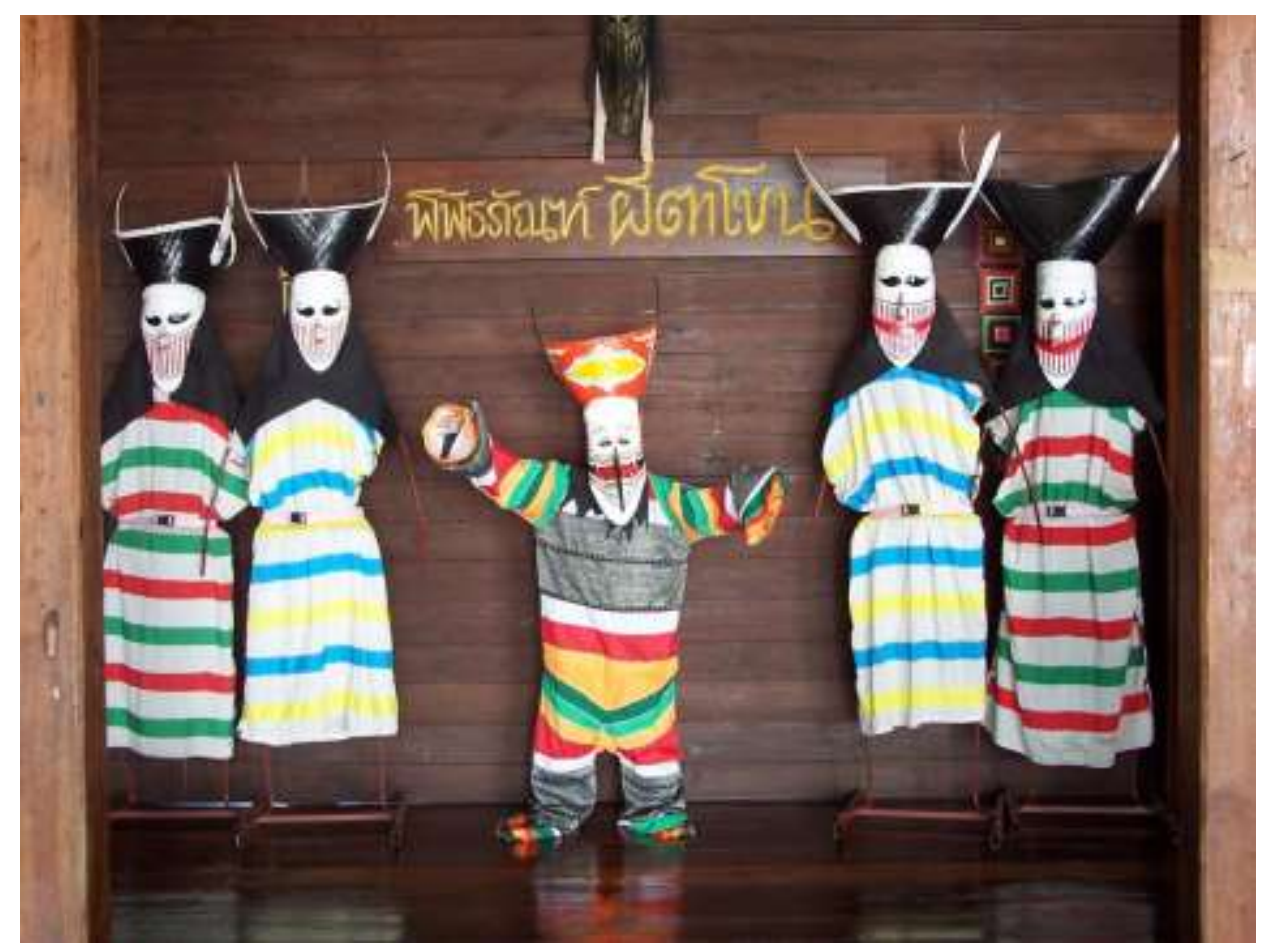

FIGURE 6. Former 'Pi Ta Khon' costumes and masks (above)

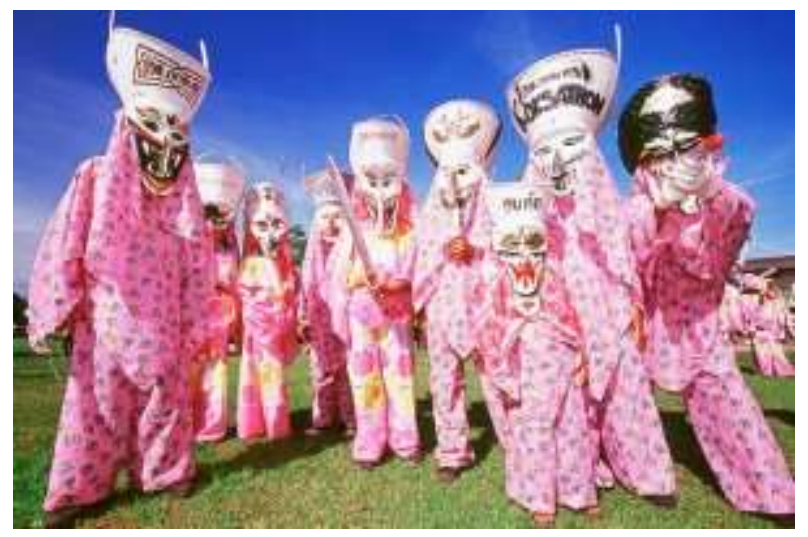

FIGURE 7. Colorful Pi Ta Khon costumes and masks for touristic entertainment (above)

\section{CONCLUSION AND RECOMMENDATIONS}

From the study result, it could be seen that like all things and all kinds of art, masked performing arts evolve through times, adapting in response to the dynamic change of social and cultural context.

This adaptation and change of masked performing arts could be divided into 2 major aspects as following.

1.Adaptation in techniques and forms (within conventional/traditional spiritual/artistic paradigm)

a. The change from painted masks to mask-like facial painting. 
This could be seen in clown's mask-like facial painting as well as kabuki facial painting mask. This adaptation could possibly help actors/performers to be able to more easily speak and have facial movements while maintaining the powerful charm of masked performance, hiding their own identities beneath the masks.

b. The revival/restoration of the ritual meaning and value of mask

This could be seen in western contemporary performing arts, like those of Edward Gordon Craig and Jacques Copeau.

2. The adaptation/change towards new paradigm: mechanistic scientific paradigm

a. Contemporary masked performing arts adaptation in response to capitalist context

This could be seen in the case study of 'Pi Ta Khon' in Thailand, as well as in several of the masked performing arts which are touristic attraction all over the world.

According to the conceptual basis of the study, which could be shown in diagram as following, media has had strong influence over human mind. Masked performing arts also have the powerful quality of media. This changing of forms and consciousness of men has greatly been affected by the continuing, everchanging social contexts. It is all part of the whole, transcending and including the old form in its emergence.

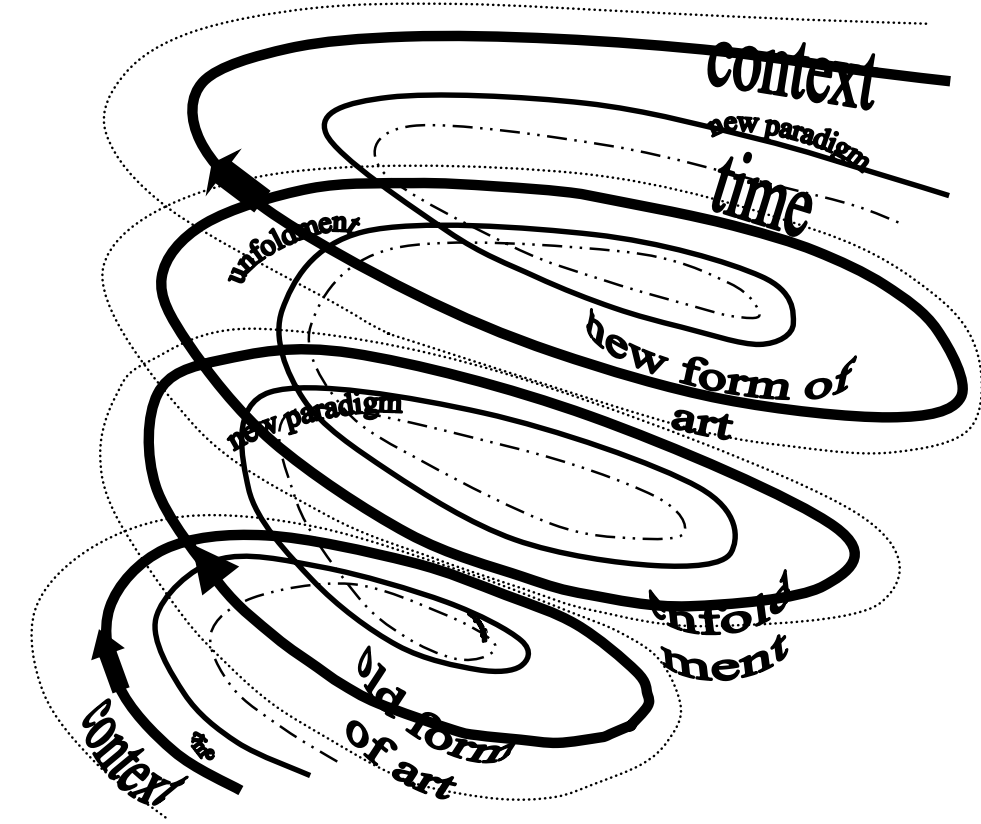


What we could question probably be how capitalist social context would affect/influence future society, both in forms and content, if the possibly emerging forms and content of the future performing arts and society would somehow transcend and include the present forms and content of capitalist influence.

From the conceptual basis of the study, at the inner level, the learning process of an individual towards spiritual development through performing arts is composed of 3 levels, that is, the preparation/confrontation level when seeing the performance, the incubation of contents received, internalizing them within, and the illumination level, the manifestation of insight or wisdom gained from such incubation.

It could be analyzed from this conceptual basis that the use of mask in performing arts for spiritual/religious and artistic purposes could help enhancing self-reflection of all parties involved to create insight/wisdom. It draws in universal energy and helps restoring holistic balance of the community, working with both physical body and mind. The confrontation of this healing energy from the masked performance, through incubation within, could give emergence to the more balanced and holistic individuals and community.

However, as for the use of mask in performance for commercial/touristic purpose, under capitalist influence, like in the case study of 'Pi Ta Khon' masked performance of Dan Sai district of Thailand, with the change of purpose and focus from spiritual to commercial one, the internal incubation for all parties involved would possibly be shifted from spiritual insight focus towards commercial profit and touristic entertainment focus. It would be hard to expect spiritual wisdom illumination/manifestation after all these previous capitalist preparation and incubation.

It thus should be aware of and take into consideration the purpose of the use of masks in performance, for what you reap would be eventually what you sow according to the universal causal law of karma.

\section{REFERENCES}

Belo, Jane. 1966. Bali: rangda and barong. Seattle, WA: University of Washington Press.

Callery, Dymphna. 2001. Through the body: A practical guide to physical theatre. London, UK: Nick Hern Books. Cameron, Kenneth M., and Patti P. Gillespie. 2003. The enjoyment of theatre. Boston, MA: Allyn \& Bacon.

Corey, Irene. 1988. The mask of reality: An approach to design for theatre. New Orleans, LA: Anchorage Press. Edson, Gary. 2005. Masks and masking: Faces of tradition and belief worldwide. Jefferson, NC: McFarland \& Co. Goswami, Amit. 1993. The self-aware universe: How consciousness creates the material world. New York, NY: G.P. Putnam's Sons.

Guba, Egon G. 1990. Paradigm dialog. London, UK: Sage.

Guénon, Rene. 2004. Symbols of sacred science. Hillsdale, NY: Sophia Perennis.

Hahner-Herzog, Iris., Maria Kecskesi, and Lazlo Vajda. 2010. African mask: The Barbier-Mueller collection. New York,

NY: Prestel Publishing.

Kusano, Eisaburo. 1967. Stories behind noh and kabuki plays. Tokyo, JP: Tokyo News Service. Lecoq, Jacques. 2002. The moving body: Teaching creative theatre. New York, NY: Routeledge.

Nonaka, Ikujiro, and Hirotaka Takeuchi. 1995. The knowledge creating company. Oxford, UK: Oxford University Press.

Nakamura, Yasuo N. 1971. The classical theatre (D.Kenny, trans.). Tokyo, JP: Weatherhill publishing.

Polanyi, Michael. 1969. Knowing and being. Chicago, IL: University of Chicago Press.

Reinert, Otto. 1970. Classic through modern drama. Boston, MA: Little, Brown \& Company. 
Rozik, Eli. 2003. The ritual origin of Theatre-A scientific theory or theatrical ideology? The Journal of Religion and Theatre 2, no. 1:1-3.

Sannes, G.W. 1970. African 'primitives': Function and form in African masks and figures (M.King, trans.). London, UK: Faber and Faber.

Schechner, Richard. 1988. Performance theory. London, UK: Routledge.

Smith, Melanie K., and Mike Robinson. 2006. Cultural tourism in a changing world: Politics, participation and (Re) representation. Toronto, NA: Channel View Publications.

Vallibhotama, Srisakra. 2007. Ghosts and Buddhism, religion and belief in Dan Sai society: The spiritual equilibrium of local people of Mun River. Bangkok, TH: Lek-Prapai Foundation.

Thompson, Charmagne, and Mary French. 2003. Mask around the world. URL: https://goo.gl/vKLuSG (accessed on May 1,2016).

— This article does not have any appendix. - 